AUTHORS:

Aletta E. Schutte ${ }^{1}$

Caradee Y. Wright ${ }^{2}$

Genevieve Langdon ${ }^{3}$

Christine Lochner ${ }^{4}$

Bronwyn Myers ${ }^{5}$

\section{AFFILIATIONS:}

${ }^{1}$ Hypertension in Africa Research Team, Faculty of Health

Sciences, North-West University, Potchefstroom, South Africa

${ }^{2}$ Climate Studies, Modelling and Environmental Health Research Group, Council for Scientific and Industrial Research, Pretoria,

South Africa

${ }^{3}$ Department of Mechanical Engineering, University of Cape Town, Cape Town, South Africa ${ }^{4}$ MRC Unit on Anxiety and Stress Disorders, Department of Psychiatry, Faculty of Medicine and Health Sciences, Stellenbosch University, Stellenbosch, South Africa

${ }^{5}$ Alcohol and Drug Abuse Research Unit, South African Medical Research Council and Department of Psychiatry and Mental Health, University of Cape Town, Cape Town, South Africa

\section{CORRESPONDENCE TO:}

Aletta Schutte

\section{EMAIL:}

alta.schutte@nwu.ac.za

\section{POSTAL ADDRESS:}

Hypertension in Africa Research Team, North-West University, Private Bag X6001, Potchefstroom 2520 .

South Africa

\section{KEYWORDS:}

postgraduate; supervisor; funding; bursaries; postdoctoral; mentorship; academia

\section{HOW TO CITE:}

Schutte AE, Wright CY, Langdon G, Lochner C, Myers B. What is the research experience of young scientists in South Africa? S Afr J Sci. 2013;109(11/12), Art. \#a0040, 2 pages. http://dx.doi. org/10.1590/sajs.2013/a0040

(C) 2013. The Authors. Published under a Creative Commons Attribution Licence.

\title{
What is the research experience of young scientists in South Africa?
}

The results of an online survey - the SAYAS Survey of Young Scientists that involved the participation of 1021 postgraduate students and postdoctoral fellows from tertiary institutions in South Africa - were released in a report launched in November 2013. In this commentary we highlight some of the key findings from the report: The Research Experience of Young Scientists in South Africa. ${ }^{1}$

\section{The SAYAS Survey of Young Scientists}

The South African Young Academy of Science (SAYAS) was launched in 2011. SAYAS was borne out of the need for young scientists to contribute towards solutions to national and global challenges facing society. This diverse group of young academics was created after a stringent process of individual selection, executed and administered by the Academy of Science of South Africa (ASSAf). Part of SAYAS's mandate is to act as the voice for young scientists in South Africa. In order to fulfil this mandate, the Young Academy requires a deeper understanding of the needs and challenges of young scientists in the country; a requirement which motivated this project - a survey that focused on the profile and research experience of postgraduate students and postdoctoral fellows in South Africa.

Following approval from the Health Research Ethics Committee of Stellenbosch University and the Nelson Mandela Metropolitan University, the survey was distributed online via the research administration offices of all tertiary institutions, and was open for anonymous responses for approximately 4 months (September 2012 to January 2013).

\section{Key findings from the survey}

The key findings from the survey are presented in Table 1. In this commentary we focus specifically on the first key finding, namely that $43 \%$ of respondents indicated that their reason for pursuing postgraduate studies was the desire to pursue an academic career (Figure 1). (Please note that all key findings are discussed in detail in the full report. $\left.{ }^{1}\right)$

Table 1: $\quad$ Key findings from the SAYAS Survey of Young Scientists

1. From the 1021 respondents, $435(43 \%)$ indicated that the reason for pursuing postgraduate studies was the desire to pursue an academic career. This proportion increased to $58 \%$ among PhD students and postdoctoral fellows.

Quality features high on the agenda of young scientists - rated the most important in terms of institution and

2. supervisor choice. The majority prefers an institution that provides high-quality teaching and research, and a supervisor who is regarded as an expert in their field of study.

Young scientists are well aware of the need to publish research results. Over $50 \%$ ranked courses in writing for 3. publication as important for their development as young scientists, thereby flagging this need as an important one for institutional support.

The majority of respondents (83\%) indicated that they see the value of having a mentor in addition to their supervisor.

4. Young scientists with at least one mentor were $46 \%$ more likely to report good or excellent academic progress (rather than very poor, poor or adequate progress) compared to those without mentors $(p=0.007)$.

Most young scientists (64\%) afforded their studies by making use of bursaries, either as a stand-alone source or in 5. combination with other support. In open-ended responses, young scientists placed significant emphasis on the need for adequate financial support. Arguably, these results highlight that the number of postgraduate students in South Africa will not increase if more bursaries are not made available.

Honours, master's and doctoral students and postdoctoral fellows are collectively referred to as 'young scientists'.

Interested in an academic career To gain a better salary/job

Trying to ensure that I will find a job Not sure on where to start finding a job I was offered funding to do so Not ready to go and work yet

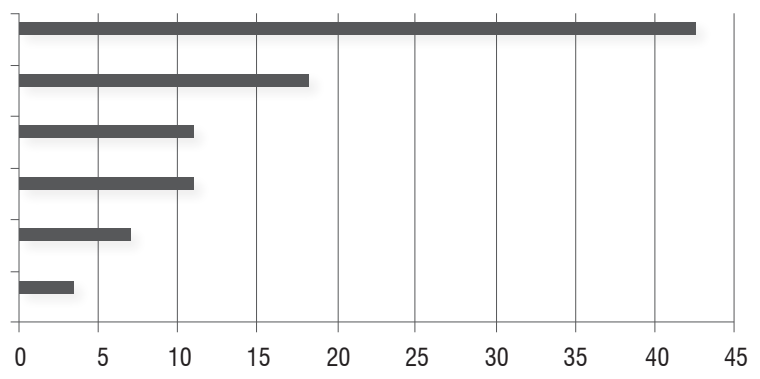

Figure 1: Responses (\%) to the question: 'What is your reason for doing postgraduate studies?' 
There seems to be a knowledge gap regarding the developmental needs of the country and career planning by young scientists. Key national strategy and policy documents, such as the National Development Plan $(2011)^{2}$ and the National Research Foundation's document titled 'Scaling-up the South African Research Enterprise' (2011) ${ }^{3}$, urge expansion in the production of highly skilled professionals, especially PhDs, to improve South Africa's research and innovation capacity. These expansions include the implementation of interventions to grow the number of graduates produced in South Africa to an ideal $6000 \mathrm{PhDs}$ per annum in 2020-2030. These important strategies were partly based on one of the main outcomes of ASSAf's The PhD Study, which was to escalate doctoral graduates, because South Africa has a relatively low doctoral graduation rate. ${ }^{4}$ For example, South Africa produced 26 doctorates per million persons in 2007 (a total of 1274 doctoral graduates), which was considerably lower than those of Turkey (48 per million persons) and Australia (264 per million persons).

While the key national strategy and policy documents, and the broader established scientific community, realise the importance of increasing the number of PhDs in South Africa in order to address the demand for high-level skills in our emerging economy, our results show that large numbers of postgraduate students have career aspirations in academia. The percentage of young scientists interested in an academic career increased from $24 \%$ at honours level to $34 \%$ at master's level and $58 \%$ at $\mathrm{PhD}$ and postdoctoral levels. It is highly unlikely that South Africa's tertiary education sector will be able to accommodate these young scientists into academic positions. In fact, the number of faculty positions in academia has remained constant for many years; the headcounts of permanent professional staff at higher education institutions were 20072 in 2005 and 22759 in 2011 - a mere increase of 2687 over 6 years (13\%). ${ }^{5}$ Moreover, apart from two new universities planned for Mpumalanga and the Northern Cape, no large-scale expansion of teaching and research staff at higher education institutions has been identified in the National Development Plan. ${ }^{2}$

It is important to reflect or speculate on the possible reasons for this knowledge gap, specifically why such a high percentage of young scientists is interested in an academic career whilst there is an outcry for more PhDs in the research and innovation industry? This needs to be addressed by future investigations, but we could speculate that young scientists may not be aware of career opportunities in industry, or they may be hesitant to become 'overqualified' for the available positions in industry. Also, because of the high teaching and postgraduate student supervision demands on the time of academic staff, ${ }^{6}$ there is a lack of mentorship guiding young scientists on their career options. Efforts by industry to have a presence in academic institutions may also bring specific career opportunities to the attention of students, guiding career planning from undergraduate level onwards. Tertiary institutions may have to increase their guidance in assisting students to create appropriate career paths. This mismatch between the career aspirations and opportunities for postgraduate students may lead to potential unhappiness if expectations are not properly managed and if alternative careers in government and industry are not promoted.

Apart from the first key finding, several results suggest that if important strategic interventions are not made, South Africa will not be able to reach its target of $6000 \mathrm{PhDs}$ per annum in the next 20 years. One of these findings is that $64 \%$ of young scientists afforded their studies through bursaries - either as a stand-alone source or with other support; their open-ended responses consistently emphasised the need for adequate financial support in order to continue with their studies. Approximately $75 \%$ of respondents received less than $5 \mathrm{~h}$ of supervision per month - a similar result to that of The PhD Study ${ }^{4}$ which reported that $73 \%$ of $\mathrm{PhD}$ students received less than $2 \mathrm{~h}$ of supervision per month. Wingfield ${ }^{6}$ argues that ideally $16-25 \mathrm{~h}$ should be spent per month on
PhD supervision. One possible explanation for our finding on supervision time is that the burden on academic staff to supervise numerous students and increase their publication output amongst their teaching duties makes it impossible to supervise students for more than $5 \mathrm{~h}$ per month. It may be argued that the expansion of academic staff members is needed to reach the target of $6000 \mathrm{PhDs}$ per annum. Another finding is that young scientists realise the importance of quality in terms of the research institution and of having a supervisor who is regarded as an expert in their field of study, which indicates that expert academic staff may become overburdened with postgraduate students, leading to lower quality outputs, or students being denied postgraduate studies as a result of limited capacity.

Results from this survey should, however, be interpreted within the context of its limitations and strengths. The majority $(65 \%)$ of responses were from White respondents, with $20 \%$ of responses from Black respondents, indicating overrepresentation of White and underrepresentation of Black young scientists based on national enrolment figures ${ }^{3}$ of $19 \%$ and $59 \%$, respectively. The percentage of respondents enrolled in natural science courses (39\%) was higher than the national enrolment of $11 \%{ }^{3}$. Also, approximately $70 \%$ of the respondents originated from four of the largest tertiary institutions (Universities of Stellenbosch, Pretoria, Cape Town and the North-West). Strengths of the study are that the 1021 responses compare well to those of the survey of doctoral graduates reported in The PhD Study in which 1076 responses were obtained; and that the respondents ranged from a broad field of disciplines and registration categories (honours, master's and PhD students, as well as postdoctoral fellows).

To conclude, the SAYAS report, The Research Experience of Young Scientists in South Africa, brings to light new insights into how young scientists perceive the academic environment, and flags several areas for intervention for tertiary institutions, government and industry to take South Africa one step closer to obtaining a more supportive and fertile research environment for young scientists. These areas are (1) increased academic staff capacity to accommodate the planned increases in postgraduate students; (2) clear information guidance from tertiary institutions for undergraduate and postgraduate students regarding scholarships and bursaries, as well as career opportunities; (3) institutional support for young scientists in terms of courses for the writing of research publications and formal mentorship programmes; and (4) better engagement between industry and tertiary educational institutions to increase the understanding of possible career pathways in South Africa.

\section{References}

1. South African Young Academy of Science (SAYAS). The research experience of young scientists in South Africa. Pretoria: SAYAS; 2013.

2. National Planning Commission. National Development Plan: Vision for 2030. Pretoria: National Planning Commission; 2011.

3. National Research Foundation. Scaling-up the South African research enterprise: 2011-2020. Pretoria: National Research Foundation; 2011.

4. Academy of Science of South Africa (ASSAf). The PhD study: An evidencebased study on how to meet the demands for high-level skills in an emerging economy - Consensus report. Pretoria: ASSAf; 2010.

5. Department of Higher Education and Training. Management and Information Systems [homepage on the Internet]. No date [cited 2013 Oct 21]. Available from: http://www.dhet.gov.za/Structure/Universities/ ManagementandInformationSystems/tabid/419/Default.aspx

6. Wingfield B. How much time does it take to supervise a PhD student? S Afr J Sci. 2012;108(11/12), Art. \#1454, 2 pages. http://dx.doi.org/10.4102/sajs. v108i11/12.1454 